\title{
NATURAL RUBBER LATEX AS A RESIST MEDIUM FOR BATIK PRODUCTION
}

\author{
A. E. Asmah ${ }^{1} *$, V. Okpattah, ${ }^{2}$ and E. Koomson ${ }^{3}$ \\ 1, \& 2. Department of Integrated Rural Art and Industry, KNUST, Kumasi \\ ${ }^{3}$ Department of Educational Innovations in Science \& Technology, KNUST, Kumasi \\ *Corresponding author: ekowasmah@yahoo.co.uk
}

\begin{abstract}
To reduce the dependency of the exportable Paraffin wax, as a major resist component in batik making, the study examined the possibility of using the locally available natural rubber latex extracted from the natural rubber tree as a resist medium for batik production. A series of experiments were conducted using the rubber latex on mercerized cotton as a resist via stamping, tjanting and screen printing techniques. The experimental and descriptive methods under the qualitative research approach were the main instrument deployed. It was realized based on the various experiments conducted, that the natural rubber latex coagulates when expose to air, making its application difficult to adhere well on the fabric. To resolve this, a concentrated ammonia solution and poly vinyl acetate were added to the freshly tapped natural rubber latex to prevent coagulation, prolong its liquid state and improve its viscosity to make it applicable onto the cotton fabric. Though the unpleasant smell remains after de-latex, the project proved successful after a series of washing to reduce the smell of the turpentine. Further research is suggested to examine how the smell of the turpentine can be reduced to avoid eroding the brightness of the dyed fabric, especially when dyed with lighter colours such as orange and yellow.
\end{abstract}

Keywords: Natural rubber Latex, ammonia solution, poly vinyl acetate, mercerized cotton, batik.

\section{INTRODUCTION}

Batik, a method of textile decoration is a creative form of self-expression in fabric design, using techniques such as resist dyeing, mordant printing and painting. It is also a form of resisting decorative technique, and a fabric dyeing method which uses wax or paste to create patterns and designs (Asmah et. al. 2015). The designs are transferred on fabrics when melted wax or prepared paste is applied in areas of the cloth to prevent them from absorbing colour when the fabric is dipped into a dye bath.

Butterworths (1967), and Ripayandi (2009), explain that the word batik describes a sort of resist printing known and studied as a native craft in Java, South East and parts of Africa. It is well known in Japan, India and Indonesia (Fraser-Lu, 1986). However, it is by its Indonesian name of batik that the process is best 


\section{Asmah et al.}

known. Growth in craftsmanship has borne testimony to mankind inmate craving to design on substrates, to exhibit creativity, uniqueness and a sense of identity (Asmah et. al. 2015). This finds its expression in embracing any method of applying colour or pattern to any textile fabrics. Such congealing agent like the cooked starch, wax and konkonte are essentially used to create resist forms especially on any cellulosic fabrics. Batik making in Ghana normally uses reactive dyes, indanthrene dyes, Sulphur dyes, vat dyes and acid dyes, but the medium of resist, keeps on changing from the use of wax to uncooked starch to a mixture of cooked starch and caustic soda to create a resist on the fabric. The traditionally used resist medium, the Paraffin wax has worked over time, through many application techniques yet its use has proved very expensive, sometimes unavailable and unsafe due to its hot melted effect of the wax on contact with the human skin. Hence the need to research into a new locally available resists material to sustain the batik trade.

Empirical studies conducted on natural rubber latex gum over a span of two years has proven that it has special qualities capable of resisting dyes on cellulosic fabrics, especially mercerized cotton fabrics that may offer a better print and resist quality, superior obviously to that of the starch paste derived from cereals, stems or roots such as corn, wheat, tapioca and cassava. The general objective therefore is to ascertain its efficacy as a resist material on cotton fabric when applied via a block stamping, tjanting and screen printing.

Empirically, the introduction of natural rubber latex as a resist material for batik making is almost non-existent, but known to be used for the production of gloves, condoms, treads on vehicle tires, conveyer belts, valuable pump housings and pipes ranging from domestic clothes wringers to other medical products. Historically the properties of latex were apparently discovered by different groups of people in different areas. The Aztecs of Mexico played balls made of latex of Castilla Elastica Moraceae). In the Amazon area, the Indians waterproofed clothing by coating it with latex of Hevea brasiliensis (Euphorbiaceae). The Spanish in South America also began to use it to waterproof clothing, the list goes on and on (Seigler, 2012).

There are two types of rubber: natural and synthetic but the natural rubber latex gum used for the project on the other hand has vegetable origin, an industrial material achieved mainly from the tree called Hevea Brasiliensis belonging to Euphorbiacea family. It normally accounts for $95-98 \%$ of the rubber produced throughout the world (Yip and Cacioli, 2002). It is primarily grown in orchards in Southeastern Asia (Malaysia, India, China, Sri Lanka, Vietnam), in Western Africa (Ghana, Nigeria, Cambodia) and in North part of South America (Brazil, Guatemala). (Brydson, 1978). Apart from other institutional research rubber plantations in various parts of the country, the Government of Ghana within a span of 46 years (1971 - 2017) has established a Rubber estate in the Eastern region in the name of Rubber Plantations Ghana Limited, (RPG) with the aim of sustaining the crop. Currently RPG in the eastern region is producing 400 tons of dry rubber annually and approximately 19,500 tonnes of dry rubber from over 3000 farmers in the Western, Ashanti, Eastern and the Central regions were collated by the close of 2016 production year (Sridee, 2006).

The rubber latex is collected from a series of steps involving preservation, concentration, coagulation, dewatering, drying, cleaning, and blending. Its formation is created by the enzymatic processes, grown in warm (average monthly temperature $25-28{ }^{\circ} \mathrm{C}$ ) and humid (humidity around 80\%) climatic conditions (Kohjiya and Ikeda, 2014). The source of rubber is sucrose created from carbon oxide and water during photosynthesis process that generates a colloidal dispersion of solid particles of the polymer polyisoprene $(\mathrm{C} 5 \mathrm{H} 8) \mathrm{n}$ in water by polymerization. Chemically, Hevea Brasiliensis is practically pure poly-cis-1.4 isoprene (contains more than $99.9 \%$ of cis 1.4 structural units). (Canter, 2017). (Fig 1) 
Natural rubber latex as a resist medium for batik production... 128

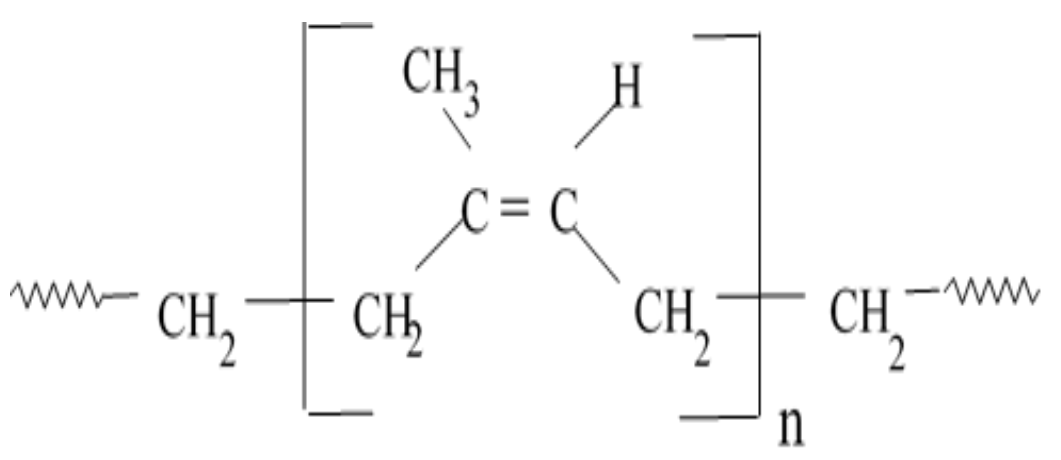

Fig. 1: Poly-cis-1.4-isoprene

(Courtesy - Rubber Chemistry. Canter, 2017)

The natural rubber achieved from fresh latex contains a small portion of gel with higher content of nitrogen and minerals mutually connected with proteins through hydrogen bridges as shown above. It has also excellent strength characteristics with long, regular, flexible and practically linear and a very good elastic properties with a spontaneous maximum crystallization rate of approximately $-25^{\circ} \mathrm{C}$. Natural rubber latex has a good dynamic performance, limited high temperature resistance (max. $+70 \mathrm{C}$ ), good low temperature properties $(-50 \mathrm{C})$ ability to bond strongly with cellulosic material and even metals. It is easy to process, has a high and excellent resistance to abrasion with greater resistance to tearing when hot or to heat buildup (Kohjiya and Ikeda, 2014). Table. 1 is the composition of freshly natural rubber latex and its content percentage by weight.

There are small amounts of proteins, resinous matters (including lipids), hydrocarbons and mineral substances (Table. 1) present in freshly natural rubber latex. These non-rubbery materials, surrounded by a surface of rubbery particles mainly proteins and lipids, gives the latex its negative charge and the stability required
$\%$ NH3) added only in very small amounts, normally $0.01-0.05 \%$. Ammonia stands out among other gases because of its great solubility in water, especially where it exists as unionized ammonia and ionized ammonia under normal circumstances; however, at lower temperatures, the vaporized ammonia condenses and dissolves in water (Ismail and Matsuura, 2012).

The other material component used in the study was the turpentine $(\mathrm{C} 10 \mathrm{H} 6)$, an organic solvent obtained by the distillation process from mainly live coniferous resin tree species to derive the semi-oleoresins fluid. This extracted substance contains a mixture of terpenes and essential oils (75-90 percent of resins and 10-25 percent of essential oils) and as the turpentine oil ages, it becomes ozonized by the formation of peroxide in the presence of air and water, a determinant to its potency and unpleasant odour and taste (Meister, 2000). Apart from being used as a solvent, the extracted turpentine is applicable to such products as tires, plastics, adhesive, flavours and fragrance, cosmetics, paints and pharmaceuticals. The choice of mercerized cotton fabric used in this project, was as a result of its high affinity for dye, the procedure being; stamping, tjanting and screen printing techniques used to create the resist via the natural rubber latex mixture onto the fabric, imply- 
Table 1: Composition of fresh NR latex

\begin{tabular}{ll}
\hline Constituent & Content, \% by weight \\
\hline Rubber & $30-40$ \\
Proteins & $1.0-1.5$ \\
Resins & $1.5-3.0$ \\
Sugar & $1.0-2.0$ \\
Minerals & $0.7-0.9$ \\
Carbohydrates & $0.8-0.1$ \\
Water & $55-60$ \\
\hline
\end{tabular}

ing that this framework retains its resist application during and after dyeing.

With previous successful experimentation on Acacia gum by Asmah, (2004) as a resist medium for batik making, natural rubber latex belonging to the same polysaccharide group advances the likelihood of the natural rubber as a potential local resist material applicable to cotton for batik production. The study, therefore, sought to explore its use as an alternate resist medium for batik making based on its physical-mechanical and dynamic properties. To achieve this, three objectives were set to firstly access the properties and characteristics of natural rubber latex as a resist medium for batik making. Secondly, to experiment on the suitability of using natural rubber latex as a resist medium for batik production and thirdly to produce an experimental batik piece on mercerized cotton fabrics using the natural rubber latex as the resist material.

In addressing the characteristics for natural rubber latex tree gum the following were observed:

The latex gum as an isoprene is almost an insoluble organic polymer, coagulates and solidifies when under atmospheric temperature, but dissolves in a solvent (Allen, 1972). Dilution with water reduces its viscosity but when ammonia solution is added, it prolongs its liquid state, allowing it to be mixed with poly vinyl acetate as its thickener into a paste consistency. This makes it easier to attain the needed resistant fluid for its application on cotton fabrics. When it cools, it becomes jelly, forming a gummy substance, which makes it potentially applicable to dye applications. Experientially, it has the ability to repel the penetration of dye solution just like starch and wax and it's capable of adhering well to cellulosic fabrics without dripping off due to its viscous nature with no adverse effect on the fabric.

Kadolph and Langford, (2007) makes an assertion that by far the batik cloth production in Ghana is the most dynamic fabric decorative enterprise today still developing new appropriate technology. This trend has acquired a new procedural dimension integrating both natural and synthetic material applications via the stamping, tjanting and screen printing techniques. Such acceptability of varied products has gained traditional approval among local batik producers irrespective of the scarcity and high cost of the foreign components in its production in the local market (Asmah et al, 2015). But the need to minimise the cost of its major material being the synthetic paraffin wax or find another substitute has become very obvi- 
Natural rubber latex as a resist medium for batik production ... 130

ous and this gave rise to the use of the locally formulated natural rubber latex mixture as a resist print paste capable of achieving the same results if not better than the paraffin wax. The concept is to introduce an alternate resist material and an unusual type of batik which adds value and excitement to batik making in Ghana.

\section{MATERIALS AND METHODS}

The study mainly employed the practice based research, depended on studio activities and engaged the experimental and descriptive methods under the qualitative research paradym. The descriptive research method was used to describe the process aligned to execute the experiment conducted towards the production of the batik using latex from the natural rubber tree. Materials used for this project were as follows; mercerized cotton, ammonias solution, polyvinyl acetate, natural rubber latex from the KNUST rubber plantation, turpentine, water, sodium hydroxide, vat dye, sodium hydrosulfide (caustic soda). Tools and equipment employed in the project were aluminium buckets, plastic bowl, plastic spoons, rubber gloves, tracing paper, gloves, stamps, tjanting tool, knife-scraper, mixing bowl, cooking bowl, pins, pens and pencils, working table, and aprons. All other materials and tools apart from the rubber latex where purchased from the $\mathrm{Ku}$ masi central market.

The scope of the study was focused on batik producers, sellers of chemicals and materials used in batik making at Adum and Patasi and tappers of natural rubber latex from the KNUST rubber plantation. A series of experiments were conducted on mercerized cotton using the rubber latex as a resist via stamping, tjanting and screen printing techniques. The activities of the experiment were recorded carefully and critical observations made. To ascertain the properties and characteristics of the Natural rubber latex as a suitable resist medium, the natural rubber latex was tested to see if it possesses the properties of a resist medium for batik making. Vat dyes were also used to verify that, the latex had the abilities to resist the dyes used.
Preliminary preparations for the resist printing

Initial experiments were conducted on the natural rubber latex to ascertain its effectiveness to accommodate dyeing and to adhere firmly onto the printed fabric during and after the resist printing process. This was extremely important as noticed, that the character of the natural rubber latex when used raw did not adhere effectively onto the fabric because of its coagulation state. To avert this coagulation state and prolong its adhesive liquid state, ammonia and polyvinyl acetate were added to increase the stickiness and viscous consistency of the latex in order to hold well into the fabric during its application as a resist. Screens developed were reinforced with lacquer on the inner part of the screen. This proved highly successful upon printing. To commence with the project, the wooden stamps and the tjanting made out of a cake of foam were also prepared. In this regard, three printing procedures consisting of (Experiment I), the stamp prints and the tjanting prints, (Experiment II) the use of screen prints and (Experiment III) the use of blocked foam prints was employed on three separate fabrics to achieve a colourful batik print design.

\section{Fabric material}

The sets of mercerized white cotton fabrics for all the printed experiments and the screened print were used as the substrate for dyeing and printing. The geometrical properties of the white cotton fabrics are given in Table 2.

\section{Dyes and chemicals}

The following chemicals and dyes were used to formulate the natural rubber latex resist print paste for the main project on the 9 metres mercerized cotton fabrics. The details of the dyes and the chemicals used for 3 metres fabric are given in Table 3.

\section{Experiment one}

The natural rubber latex was applied using the wooden stamp and the tjanting technique. Within this experiment, a sample of mercerized cotton fabric measuring 15 " x 23" inches was stretched and tugged on the working table before the latex application. A prepared Adinkra wooden designed stamp was dipped into the 
131 Asmah et al.

Table 2: Geometric parameters of $\mathbf{1 0 0 \%}$ mercerized cotton fabric

\begin{tabular}{cccccc}
\hline Fabric & Ends/c m & Picks/cm & GM. /m2 & Warp Count (Ne) & Weft Count (Ne) \\
\hline $\begin{array}{c}100 \% \\
\text { Mercerized cotton }\end{array}$ & 36 & 34 & 142 & 40 & 40 \\
\hline
\end{tabular}

Table 3: Functions, quantities of dyes and chemicals used in the natural rubber latex resist print paste and for dyeing and de-latex operations

\begin{tabular}{lll}
\hline \multicolumn{1}{c}{ Dye and Chemicals } & \multicolumn{1}{c}{ Quantity } & \multicolumn{1}{c}{ Functions } \\
\hline $\begin{array}{l}\text { Orange (1 tablespoon of red vat dye, } 2 \\
\text { tablespoons of orange vat dye) vat dye }\end{array}$ & 45 grams & Dyeing \\
Marine blue vat dye & 45 grams & Dyeing \\
Red, & 45 grams & Dyeing \\
Yellow & 45 grams & Dyeing \\
Green & 45 grams & Dyeing \\
Orange vat dye & 45 grams & Dyeing \\
Violet vat dye & 45 grams & Dyeing \\
Sodium hydrosulfide & 45 grams & Reducing agents \\
Sodium hydroxide & 45 grams & Reducing agents \\
Natural rubber latex & 710 grams & Main Resist Agent \\
Cold water (30 $\left.{ }^{\circ} \mathrm{C}\right)$ & 8 litres & Solvent for mixing/dyeing \\
Polyvinyl chloride (PVC) & $300 \mathrm{millilitres}$ & Thickener \\
Ammonia solution & $300 \mathrm{millilitres}$ & Stabilizing agent (Anti-Coagulating agent) \\
Turpentine & $1500 \mathrm{millilitres}\left(1 \frac{1}{2}\right.$ litres) & Solvent for de-latex \\
\hline
\end{tabular}

(Courtesy International System of Units)

milky natural rubber latex and transferred onto the fabric (Fig. 2) and then allowed to dry.

The vat dye recipe used was 1 tablespoons of green dye, 1 tablespoon of sodium hydroxide (caustic soda) and 1 tablespoon of sodium hydrosulfide (hydrous) mixed in a bowl of $100 \mathrm{ml}$ hot water and stirred thoroughly. The dyed colour solution was then poured into a dye bath which was filled with $1200 \mathrm{ml}$ of water and stirred. The stamped fabric was immersed into the dye solution for 5 minutes, removed, dried to allow for 5 minutes oxidation as shown in Fig. 3. The dried fabric was then placed on the working table again, this time the improvised tjanting tool made from foam, was dipped into the latex and applied on the allotted resist areas of the fabric as shown in Fig. 4.

The same procedure used in preparing the first 
Natural rubber latex as a resist medium for batik production... 132

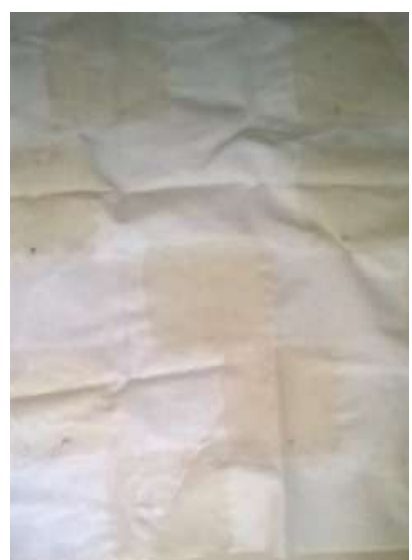

Fig. 2: Stamped fabric with the Natural rubber latex

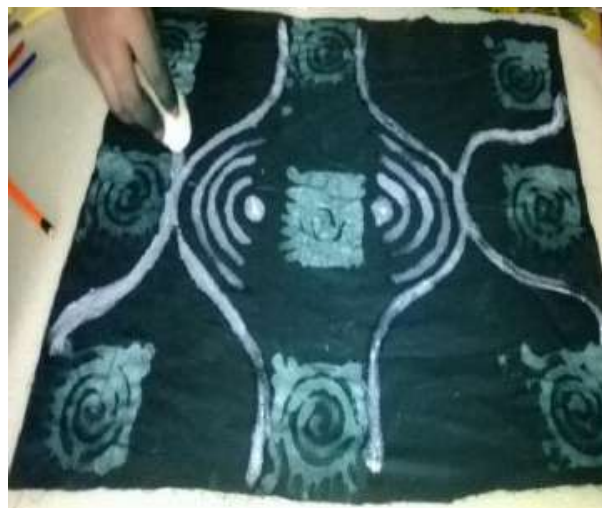

Fig. 4: Application of the Natural rubber latex on the fabric with an improvised tool

dye solution but this time, using the violet colour dye. The fabric was immersed in the dyebath for 5 minutes, removed and dried for oxidation as before. After oxidation, the rubber latex was removed from the fabric, however, unlike the wax method, where hot water or hot

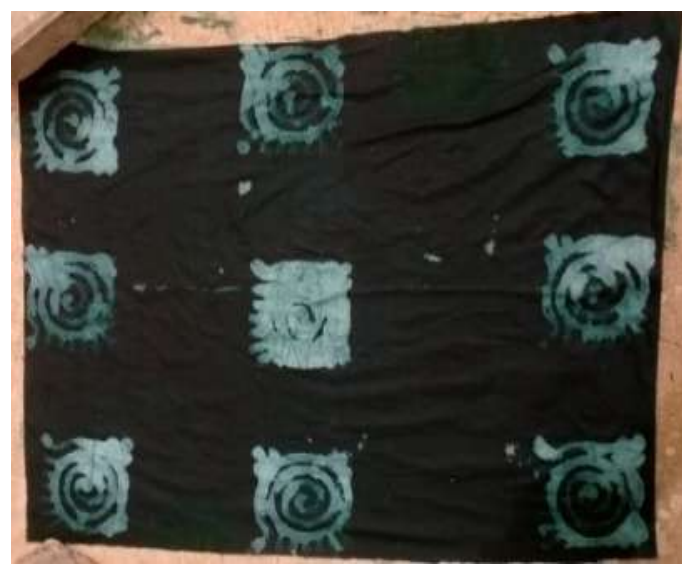

Fig. 3: Drying of the dyed fabric

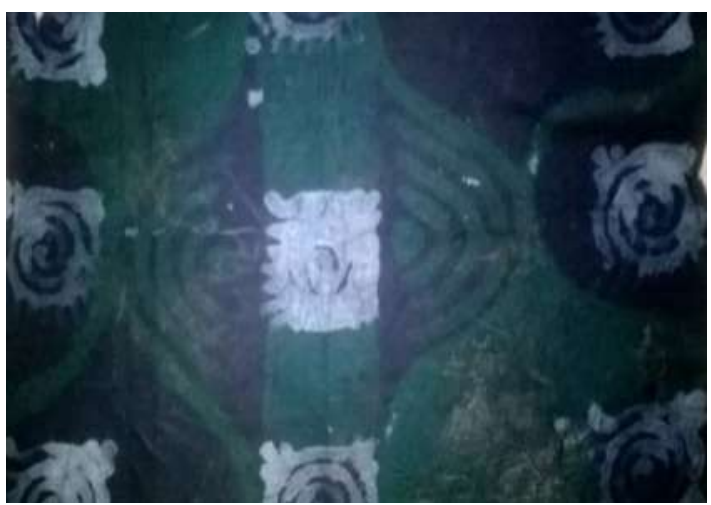

Fig. 5: The finished work

pressing iron is used to remove the wax from the fabric, 1500 millilitres of turpentine was poured into a bowl and the resist fabric, immersed, stirred and gently pressed until all of the fabric was submerged. The fabric was left in the turpentine solution for 10 minutes, 
133

\section{Asmah et al.}

stirred again and lifted up to allow the dissolved rubber latex to detach itself or flow out from the fabric or suspend on the surface of the turpentine solution. The de-latex fabric was then washed thoroughly with cold soapy water to remove the excess latex on the fabric. It was then rinsed thoroughly in clean water and dried (Fig. 5).

\section{Experiment two}

In this experiment, wooden stamp and screen printing application technique were used. For the resist paste, 50 millilitres of concentrated ammonia solution were poured into a bowl and a 300 millilitres freshly tapped natural rubber latex added to the ammonia solution as in Fig. 6.

The ammonia solution helped to prevent coagulation of the natural rubber latex. Later, 100 Millilitres of poly vinyl acetate were also added and mixed thoroughly to preserve and increase the adhesion of the natural rubber latex, as shown in Fig. 7 to attain a pasty viscosity before its application onto the fabric (Fig. 8).
An Adinkra wooden designed stamp was dipped into the latex paste, and then used to stamp the fabric measuring 11 " $\times 16$ " metres in size laid on the working table and allowed to dry under a shade. The vat dye recipe and procedure used in experiment 1 to prepare the dye solution and dye bath was repeated, but this time, half a tablespoon of each chemical was used due to the size of the fabric. The dried fabric was then immersed in the dye bath (Fig. 9) for 5 minutes and after, removed for oxidization and allowed to dry (Fig. 10).

In using the screen to transfer the paste onto the fabric, the ends of the first dyed fabric were securely stapled onto the working table, and a prepared textured screen design was placed on the fabric. A small quantity of the latex paste was poured into the reservoir at one end of the screen, and with the help of a squeegee, the paste, gently and sparingly spread with an even pressure for proper registration over the design created by the first colour print on the fabric (Fig. 11).

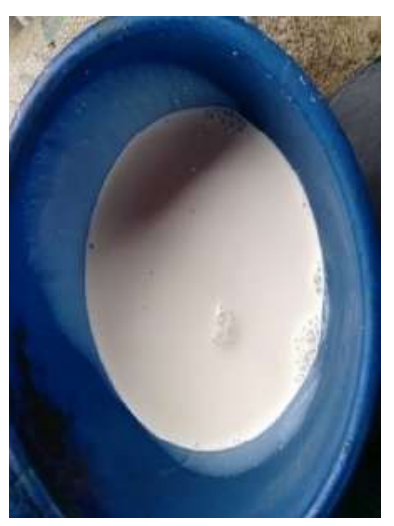

Fig. 6: Mixture of natural latex rubber with ammonia

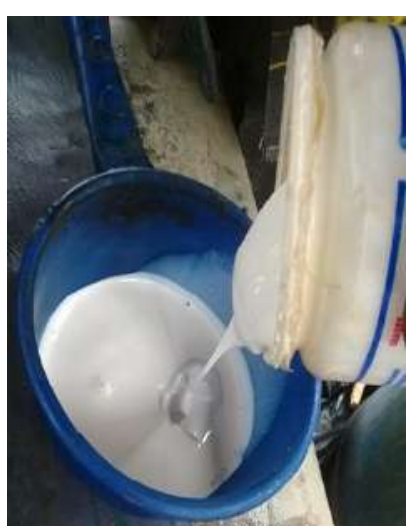

Fig. 7: Poly vinyl acetate added to the mixture of Natural rubber latex and ammonia solution

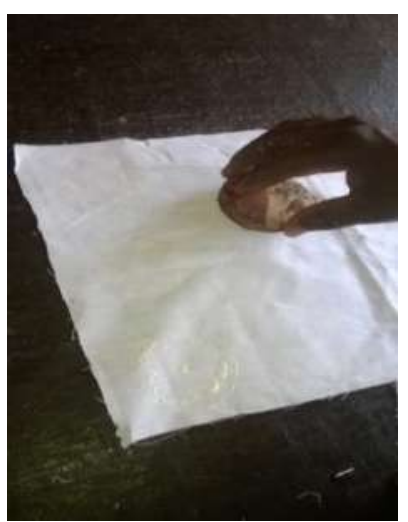

Fig. 8: Applying the latex paste onto the fabric 


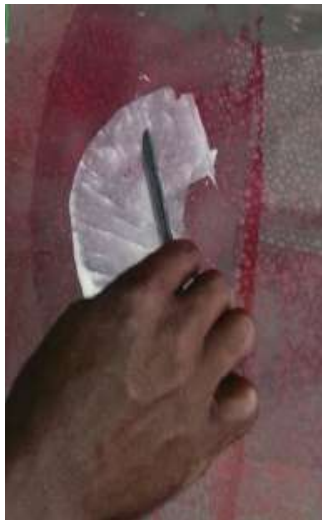

Fig. 9: Spreading the latex paste onto the fabric with a squeegee

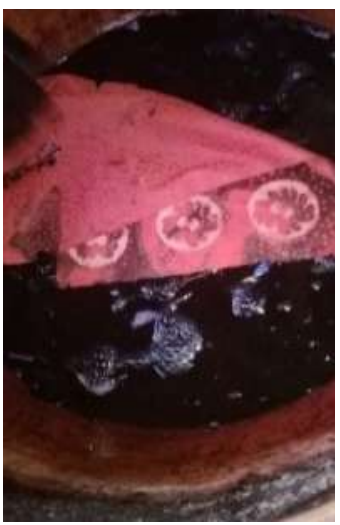

Fig. 12: Fabric immersed into the dyebath

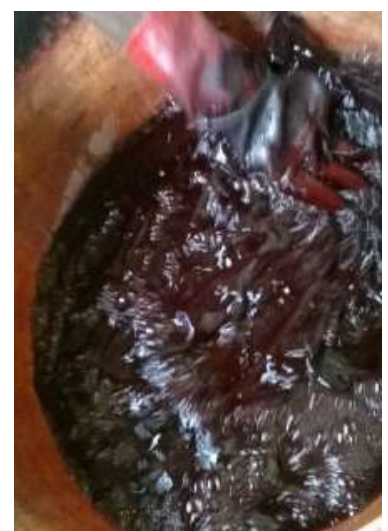

Fig. 10: The resisted fabric immersed into the dyebath bath

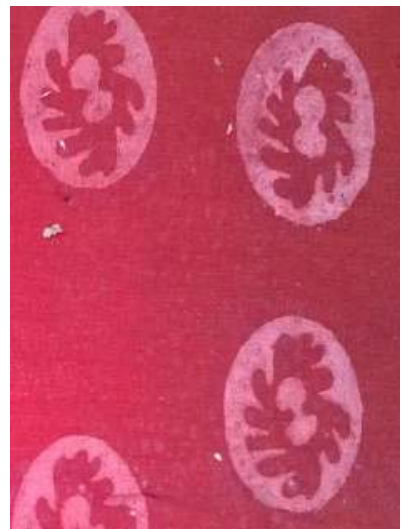

Fig. 11: The resultant effect after the dyed fabric, had been oxidized, dried and washed

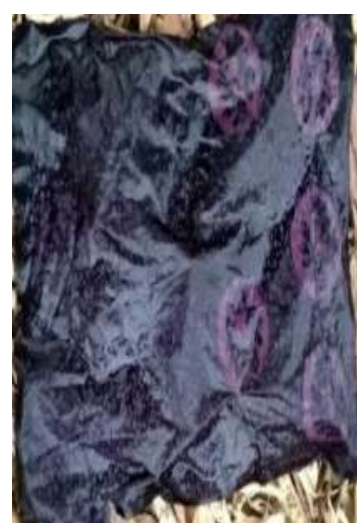

Fig. 13: Oxidizing of the dyed fabric

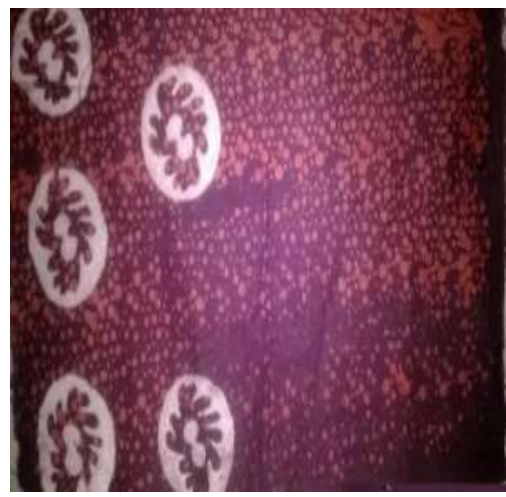

Fig. 14: Drying the de-latex fabric
After printing, the screen was carefully removed from the printed fabric, and left to dry. The last colour being the violet dye solution (Fig. 12) was prepared using the same recipe prepared as the dye solution of the first experiment. The resisted fabric was then immersed in the dye bath for five minutes, then removed and dried for oxidation (Fig. 13). The resisted dyed fabric was de-latex by pouring 250 millilitres of turpentine into a bowl and the fabric, immersed into the turpentine for 10 minutes, within this period the fabric was stirred and lifted up to allow the dissolved rubber latex to detach itself or flow out from the fabric and suspend on the surface of the turpentine solution. The de-latex fabric was then washed thoroughly, in a cold soapy water, rinsed and dried as in Fig. 14. 


\section{Asmah et al.}

\section{Experiment three}

The same natural rubber latex paste consistency used earlier for the second experiment was used for the third experiment. The fabric size of 11 " $x$ 16" inches was laid on the working table and a prepared cut out foam designed stamp was dipped into the paste, and transferred onto the fabric (Fig. 15). The resisted fabric was then allowed to dry (Fig. 16).

The leuco compound of yellow dye had a recipe of, $1 / 2$ tablespoon of yellow dye, $1 / 2$ tablespoon of sodium hydroxide (caustic soda) and $1 / 2$ tablespoon of sodium hydrosulfide mixture and transferred onto a bigger bowl containing warm water as shown in Fig. 17. The resisted fabric was then immersed in the dye bath (Fig. 18) for 5 minutes, removed and dried as shown in Fig. 19.

The resisted dyed fabric was de-latex by pouring 250 millilitres of turpentine onto the fabric in a plastic bowl, (Fig. 20) and the fabric, left in the plastic bowl containing the turpentine for 10 minutes (Fig. 21). After which the fabric was stirred, within the turpentine to enable all the parts of the dyed fabric dissociate from the latex paste (Fig. 21). The de-latex fabric was then washed thoroughly, in a cold soapy water, rinsed and dried as shown in Fig. 22.

\section{Design of the main project}

Haven successfully completed the above experiments, the researchers proceeded to address the possibility of using it in commercial quantity for the main project of producing 9 metres batik fabric using the natural latex. This involved the actualization of the design concept for the batik clothes to be produced. Per the experiment, dye recipes were formulated, fabrics were prepared, and a series of textiles designing stages such as motif development, layout, arrangement and colouring were made using geometric shapes derived from either the Adinkra symbols or from nature. The resist rubber latex paste were formulated, dyebaths prepared and the procedure for printing via designed foam and wooden stamp block, screen printing (as in Figs. 23, 24 and 25) and dyeing through table dyeing and dyeing by immersion were all planned before the commencement of the entire batik production.

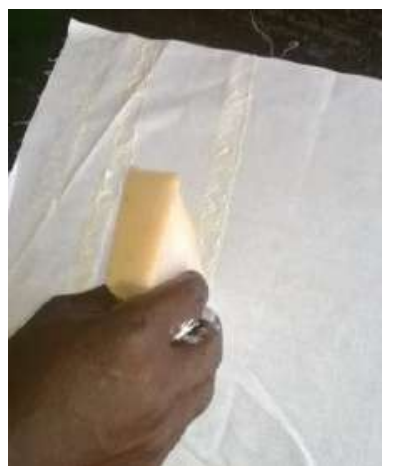

Fig. 15: Applying the paste onto the fabric using a foam stamp

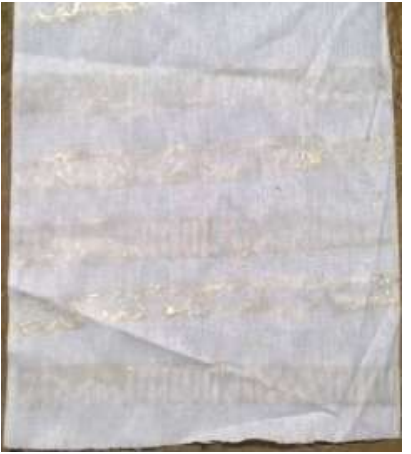

Fig. 16: Drying the resist fabric

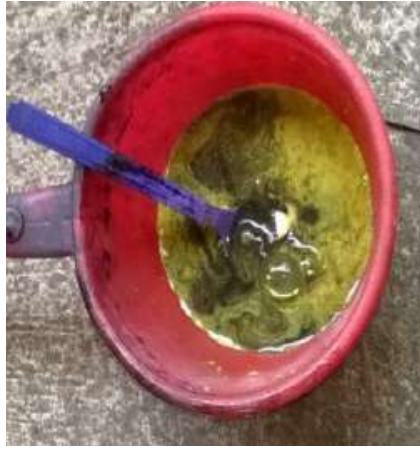

Fig. 17: Prepared leuco compound of yellow dye 


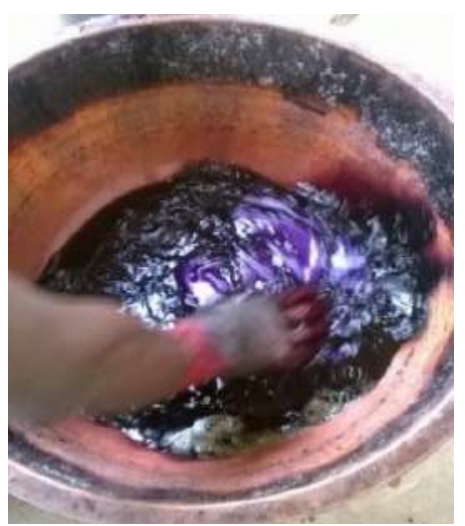

Fig. 18: Dyeing the resisted fabric

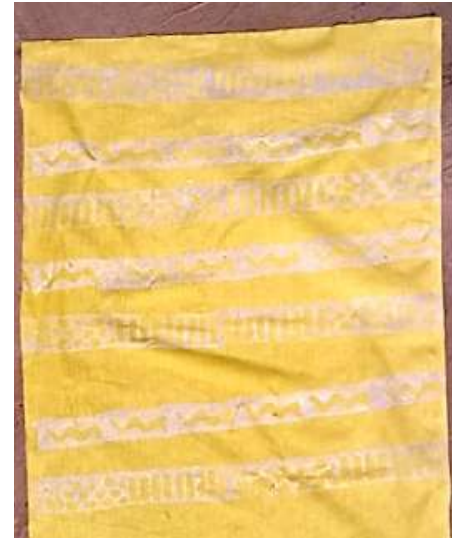

Fig. 19: Drying the dyed fabric

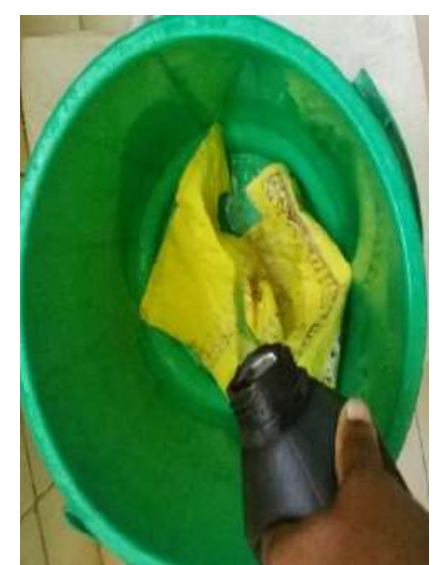

Fig. 20: Turpentine being poured onto the fabric

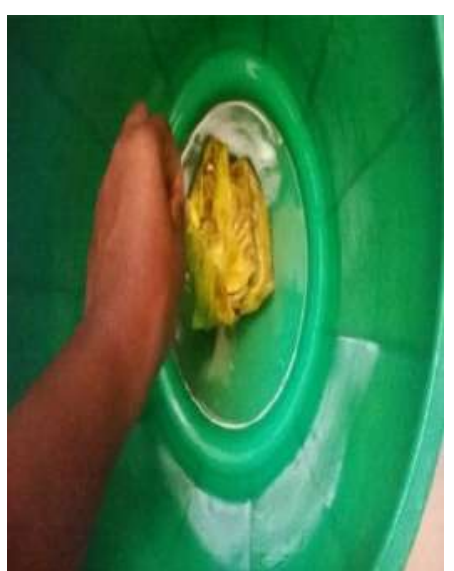

Fig. 21: Removing the latex from the fabric

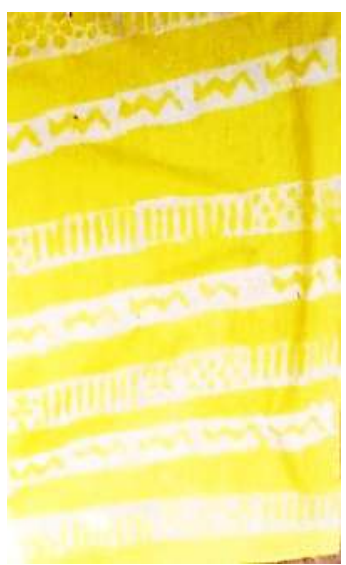

Fig. 22: De-latex fabric
With the Photoshop software, motif arrangements in a repetitive pattern were made to create an orderly design arrangement. The colours were carefully chosen to help predict the sequence of the dyeing process and how the end product would be. The illustrations below attest to the laid out design plan utilized (Figs. 26, 27 and 28).
An amount of 300 millilitres of concentrated ammonia solution was poured into a bowl, and 2 litres of freshly tapped natural rubber latex added. The ammonia was added to prevent coagulation of the natural rubber latex. 300 millilitres of poly vinyl acetate was added to preserve the natural rubber latex as well as to thicken the mixture. This was stirred thorough- 


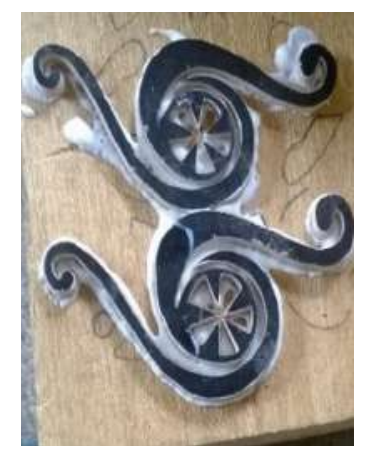

Fig. 23: Wooden stamp made out of plywood and solid wood

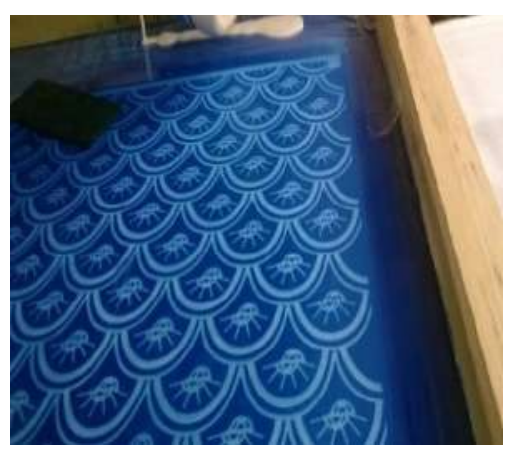

Fig. 24: A developed lacquered silk screen

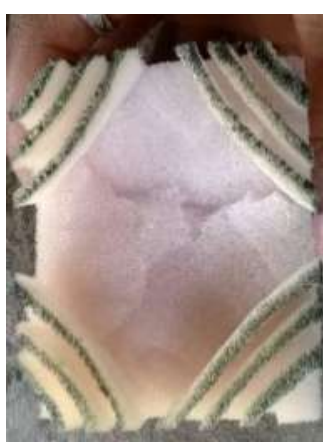

Fig. 25: A cut-out designed foam block

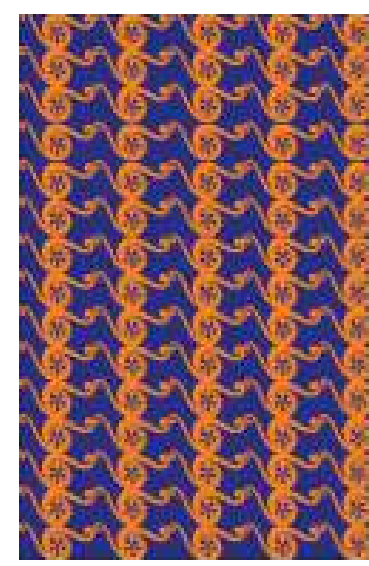

Fig. 26: Laid out design pattern 1

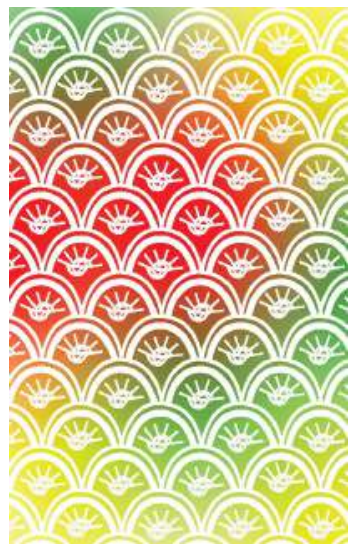

Fig. 27: Laid out design pattern 2

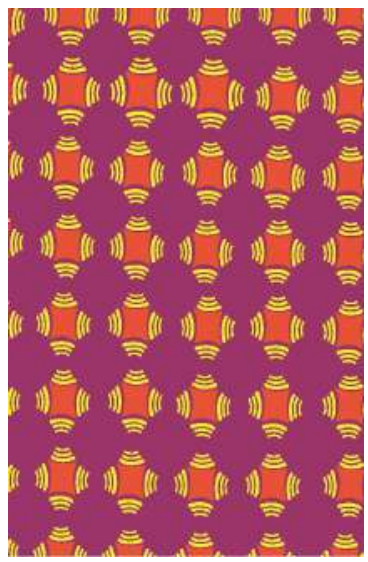

Fig. 28: Laid out design pattern 3 ly to attain the desired paste consistency needed (Fig. 29). All the preparations and well homogenized latex printing pastes were applied to the fabrics within 30 minutes of preparation (Figs. 30 and 31).

In all the three procedural categories, namely screen printing, wood stamping, and foam block prints, 3 metres fabric each were used.
With the exception of the screen printing fabric, the other two categories had their fabrics, dyed with a first colour dye. The background dye for the first project had a dye mixture of 1 tablespoon of red vat dye and 2 tablespoons of orange vat dye. The third background fabric dye had a dye mixture of 3 tablespoons of orange vat dye. All the dyeing's used in this project had a vat dye recipe by 3 tablespoons of dye, 


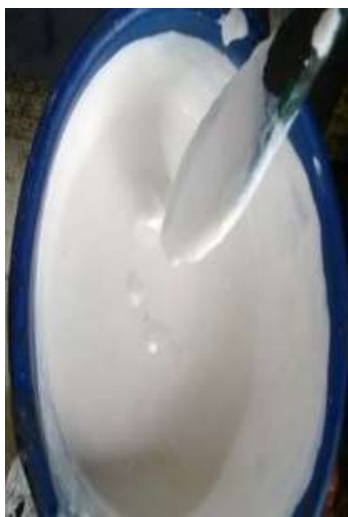

Fig. 29: Desired paste consistency

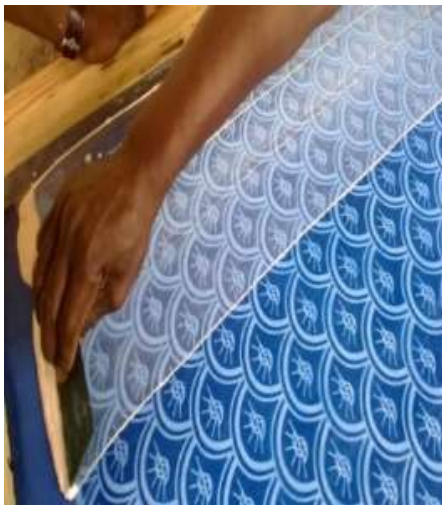

Fig. 30: Paste, screened onto the fabric

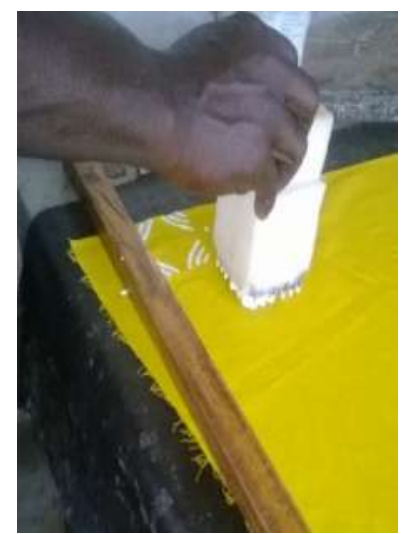

Fig. 31: Paste, stamped onto the dyed fabric
3 tablespoons of Sodium hydrosulfide and 3 tablespoons of sodium hydroxide. These recipe components were mixed by first dissolving the dye and hydrous in warm water to prevent lump formation and the caustic soda, dissolved in cold water due to its volatile nature when it comes into contact with warm water.

All the three components were mixed together and stirred before the dyeing operations. In all cases, 10 minutes were given to each dyeing process. In each case, the dye solution was poured into a half full bowl (3.5 litres) filled with cold water and the resisted fabric folded into two and immersed in the dye bath. Within the 10 minutes, the fabric underwent a stirring movement of figure 8 motion that is clockwise and anti-clock wise to ensure an even flow and even penetration of dye throughout the fabric dyeing process. The dyed fabric was then removed from the dye bath and dried to allow the dye to oxidize.

The dried, dyed fabric was removed and placed in a bowl containing water. The fabric was washed to remove excess dye and after washing, $1 \frac{1}{2}$ litres of turpentine were poured on the fabric and left in the turpentine for 30 minutes,to de-latex the fabric. Within this time, the fabric is stirred in the turpentine, to get rid of all the latex prints on the fabric. A knife, scraper was used to remove the remaining excess latex from the surface of the fabric before thorough washing was done with water. The fabric is washed again in soapy water to remove the scent of the turpentine, then finally rinsed and dried. Below are the finished works of the three projects (Figs. 32, 33 and 34).

\section{RESULTS AND DISCUSSIONS}

The raw natural rubber latex coagulates within some minutes when exposed to air. Thus made the stamping of the first experiment a bit of a challenge. It was also difficult for the improvised tjanting tool to absorb the latex since the latex coagulated around the tip of the tool, creating a ball edge, thereby making it difficult to draw thin lines. With the stamp, the edges of the design were bleeding because the latex coagulating on the surface, did not allow the design to register well on the fabric. Due to the coagulating characteristic of the latex, deep penetration into the fabric was not possible as expected. It was also realized that, the latex was not thick enough to hold onto the stamp resulting in the bleeding of the latex.

The second and third experiments saw the ad- 


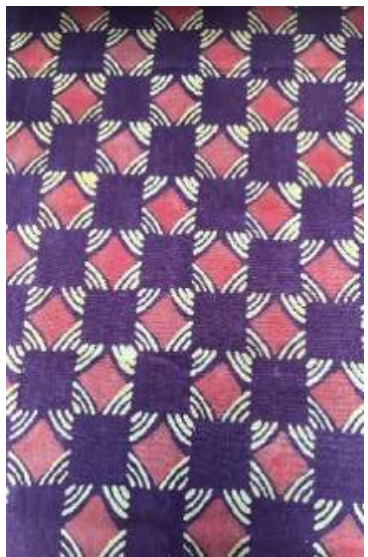

Fig. 32: Finished work of the dyed fabric, designed, and foam stamped

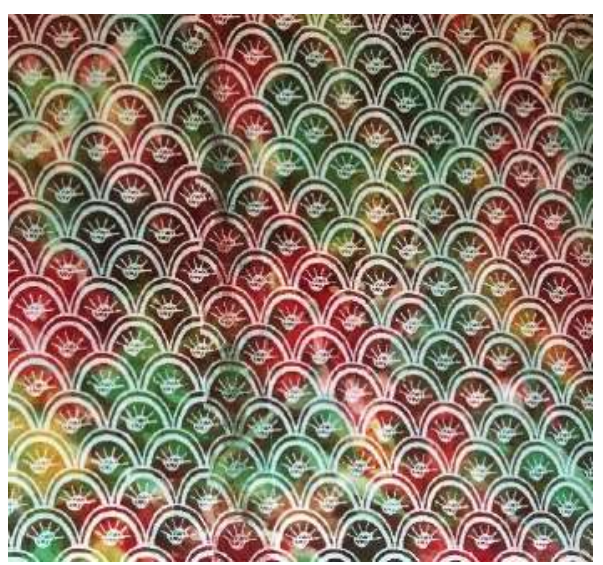

Fig. 33: Finished work of the screened designed dyed fabric

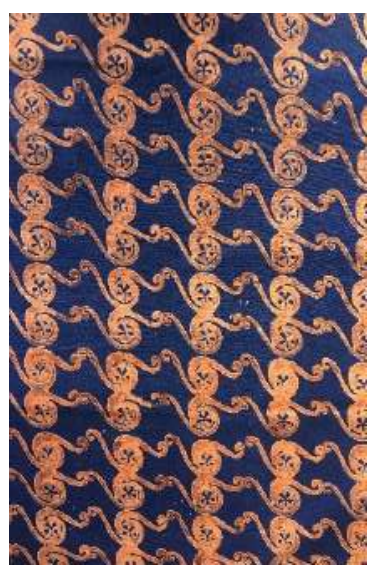

Fig. 34: Finished work of the wooden designed block dyed fabric dition of ammonia solution to the freshly tapped latex, which helped to prevent the latex from coagulating for a time span of one month (Niyogi, 2007). From the last experiment conducted, it was realized that, the poly vinyl acetate which was added to the latex increased the viscosity of the latex to form the desired paste, this helped to prevent the latex from bleeding when applied to the fabric. It was realized that, the foam stamp used for applying the latex onto the fabric was able to absorb the resist paste, which gave ease to stamping and avoided bleeding off excess paste. From observations, the patterns of experiment 2 and 3 had a sharp edge appearance and did not create any crack effect as in the case of wax resist, after the removal of the paste. Lastly, it was easier and faster to de-latex the screen printed areas of the fabric since those areas had less paste there.

Observations made from the experiments conducted, indicate that natural rubber latex possesses similar characteristics as the resist mediums traditional used for batik making. Unlike wax which has to be used in a hot molten state and starch in a cooked form, the latex as a resist must be mixed with ammonia solution and white glue before use. The ammonia substance used to prevent coagulating of the latex whiles the poly vinyl acetate (white glue) increases the stickiness of the latex in order to hold well into the fabric when applied and also thickens the latex into an applicable paste consistency.

Asmah et al, 2015 indicates that the resist medium offers a temporary barrier for colouring fabrics and areas of the resist medium are sealed to prevent those portions from receiving the dye when dipped into a dye bath or introduce to a dye solution. This is also true of the properties and characteristics of natural rubber latex when manipulated into a resist paste for batik making as this project endorses its suitability as a resist medium. Surprisingly, none of the contents of its constituents within the natural rubber latex (Table. 1) indicated any hindrance to the manipulated latex paste used for the project. Its viscosity was sufficiently high to prevent rapid diffusion of the colour through the fabric, to avoid poor print definition outlines (Rajabi and Amad, 2013: Asmah et al, 2015). It also showed a stable paste viscosity, which allowed an even and measured flow, especially through the screen. The viscosity stability was not only durable in terms of the time during fabric printing, but even through 
the dyeing process, (Pfaff, 2008). The resultant cohesiveness ensured that the strength and the free flowing quality of the paste remained intact after its application and its execution (Radley, 1976). It is however recommended that further research be done on; (1) finding easier and faster methods of removing the latex from the fabric when dyed, (2) using other dyes other than vat dyes and other types of fabrics other than cotton with the natural rubber latex to ascertain their possibilities of using them for batik making. Research could also be made to; (3) find less costly alternate solvent for the removal of the latex from the dyed fabric and at the same time find less costly yet effective chemical to prevent the coagulation of the latex.

\section{CONCLUSIONS}

Per the experiments, this resist medium has proved to be a very good resist material for batik making. Thus, for any material to be used as a resist, must be able to repel dye and resist dye penetrating into those resisted areas of a substrate. The research has also proven that like the traditional resist materials, latex paste imparts adhesiveness and softness to the printed fabric so becoming applicable to the fabric surface without spreading. Its capability to maintain its position under excessive pressure, forces the dye particles to adhere to its desired place on the fabric until the transfer of the dye into the fabric and its fixation are complete, thus making latex paste an excellent alternate resist medium for batik production. Significantly, the outcome creates the possibility of minimizing the use of synthetic resist medium, and reduce its importation drastically. This project thus serves as a platform for further exploration of similar tree latex for batik making. Its satisfactory results, no doubt will encourage local batik entrepreneurs to express with ease, their batik production activities to support and provide livelihood for economic sustenance (Asmah et al, 2015).

\section{ACKNOWLEDGMENT}

This research paper acknowledges the following for their personal involvement in the execution of the project. The assistance of Miss. Eugenia Acheampong and Mr. Jeffrey Nimo Mfum at KNUST rubber plantation, Kumasi is appreciated.

\section{REFERENCES}

AJP, R. D. (2009). A brief description on the role of batik for Indonesian Society. http://repository.usu.ac.id/bitstream/ handle/123456789/13407/09E02414.pdf

Allen, P. W. (1972). Natural Rubber and the Synthetics. Halsted Press. Pp 33. New York: Wiley

Asmah, A. E, Okpattah V. and Frimpong, C. (2015). Asoo: An innovative Print- Dyeing. Colouration. Online International Journal of Art and Humanities, 4 (3): 41-47. http:// www.onlineresearchjournals.org/IJAH

Asmah, A. E. (2004). Batik and Tie-dye for Teachers. Unpublished M. Phil. Thesis, Kwame Nkrumah University of Science and Technology, Kumasi.

Brydson, J. A. (1978). Rubber chemistry. Applied Science Publishers. London

Butterworths, H. (1967). An Introduction to Textiles, Printing, 2nd Ed. Butterworth \& Co. (Publishers) Ltd, London.

Canter, N. (2017). Manufacturing tires from renewable resources. Tribology and Lubrication Technology, 73(6): 20.

Fraser-Lu, S. (1986). Indonesian batik: Processes, patterns, and places. Oxford University Press, USA.

Ismail, A. F. and Matsuura, T. (Eds.). (2012). Sustainable membrane technology for energy, water, and environment. John Wiley \& Sons. Chapter 27, Pp 309 - 317.

Kadolph, S. J. and Langford, A. (2007). Textiles Pearson Education, Inc. Upper Saddle River, New Jersey.

Kohjiya, S. and Ikeda, Y. (Eds.). (2014). Chemistry, manufacture and applications of natural rubber. Elsevier. Woodhead Publishing.

Meister, J. J. (2000). Introduction to Polymer 


\section{Asmah et al.}

Modification. PLASTICS ENGINEERINGNEW YORK-, 60, 1-20.Butterworths, (1967). An Introduction to textiles, printing, $2^{\text {nd }}$ Ed. Butterworths \& Co. (Publishers) Ltd, London.

Niyogi, U. K. (2007). Natural and Synthetic Rubber. www. niscair.res.in

Pfaff, G. (2008). Special effect pigments: technical basics and applications. Vincentz Network $\mathrm{GmbH} \& \mathrm{Co} \mathrm{KG}$.

Radley, J. A. (Ed.). (1976). Industrial uses of starch and its derivatives (pp. 26-28). London: Applied Science Publishers.

Rajabi, M. and Amad, I. (2013). Towards a Cross Cultural Design by Integrating Batik Motifs into the Persian Carpet Design. Inter- national Journal of the Malay World and Civilisation, 2 (2): 111-112.

Seigler, D. S. (2012). Plant secondary metabolism. Springer Science \& Business Media.

Sridee, J. (2006). Rheological properties of natural rubber latex. Thesis: Master of Engineering (Polymer Engineering). Suranaree University of Technology, Nakhon Ratchasima, Thailand.

www.ghanastar.com/business/grel-to-buy19500-tonnes-of-dry-rubber (Sep 16, 2016).

Yip, E. and Cacioli, P. (2002). The manufacture of gloves from natural rubber latex. Journal of Allergy and Clinical Immunology, 110 (2): S3-S14. 